\title{
O Ensino de Biologia com enfoque CTSA: Uma Abordagem sobre Educação Ambiental e Sustentabilidade no Ensino Médio da Rede Pública do estado do Ceará
}

\author{
Focused Biology Teaching STSE : An Approach to Environmental \\ Education and Sustainability in the High School of the Public Network \\ of the State of Ceará
}

\begin{abstract}
Francisca Samara Muniz dos Santos (samara10muniz@yahoo.com) Graduada pela Universidade Regional do Cariri - URCA
\end{abstract}

Leonardo Alves de Lima (leooliimaa1 @gmail.com) Graduando pela Universidade Regional do Cariri - URCA

Luiza Maria Valdevino Brito (luizavbrito@yahoo.com.br)

Mestra em Desenvolvimento Regional Sustentavel - PRODER, pela Universidade Federal do Cariri - UFCA

Norma Suely Ramos Freire Bezerra (norma.freire@urca.br)

Mestra em Educação pela Universidade Lusófona de Lisboa

Patricia Almeida Tavares Gonçalves (patbarbalha@ hotmail.com)

Pós Graduada em Educação Ambiental com Ênfase na Diversidade, pelo Instituto Federal do Ceará - IFCE

Cicero Magerbio Gomes Torres (cicero.torres@urca.br)

Doutor em Educação Pela Universidade Federal do Ceará - UFC

Resumo: Ao longo dos anos o Ensino de Biologia tem sofrido muita influência externa, principalmente no que se refere a sua contribuição científica, tecnológica, social e ambiental, visto que existiram muitas modificações no meio ambiente e torna-se necessário repensar os impactos dos nossos hábitos de consumo, bem como a relação homem e ambiente. Diante deste contexto, este trabalho analisou como o Ensino de Biologia e a Educação Ambiental associada à sustentabilidade tem contribuído para formação de estudantes no contexto Ciência, Tecnologia, Sociedade e Ambiente (CTSA), analisando as concepções dos estudantes e promovendo reflexões sobre a importância de se trabalhar estas temáticas de modo interdisciplinar. A metodologia empregada foi quali-quantitativa e exploratória e para análise de dados foi usada a descrição etnográfica. Os dados da pesquisa revelam que a escola tende a limitar estas abordagens apenas a disciplina de Biologia, o que restringe a compreensão e os espaços para debates. Através deste estudo observa-se que há uma necessidade de se repensar o currículo escolar, e a forma de trabalhar a educação ambiental por meio da interdisciplinaridade afim de que os debates sobre meio ambiente e sustentabilidade esteja dentro do contexto CTSA, promovendo nos estudantes uma formação que impulsione práticas sustentáveis na escola. 
Palavras-chave: Sustentabilidade; Ciência, Tecnologia, Sociedade e Ambiente; Educação Ambiental; Interdisciplinaridade.

Abstract: Over the years, biology teaching has suffered a lot of external influence, especially with regard to its scientific, technological, social and environmental contribution, since there have been many changes in the environment and it is necessary to rethink the impacts of our consumption habits, as well as the relationship between man and environment. In view of this context, this paper analyzed how biology teaching and environmental education associated with sustainability has contributed to the formation of students in the context of Science, Technology, Society and Environment (STSA), analyzing the students' conceptions and promoting reflections on the importance of working on these themes in an interdisciplinary way. The methodology used was exploratory qualitative and quantitative and of data analysis the ethnographic description was used. The research data reveal that the school tends to limit these approaches only to the discipline of Biology, which restricts understanding and spaces for debates. Through this study it is observed that there is a need to rethink the school curriculum, and the way of working environmental education, working the interdisciplinarity so that the debates on the environment and sustainability are within the STSA context, promoting in students a complete training aiming to work sustainable practice daily in school.

Keywords: Sustainability; Science, Technology, Society and Environment; Environmental education; Interdisciplinarity.

\section{INTRODUÇÃO}

Considerada uma das maiores potências do mundo, os Estados Unidos (EUA) exercem grande influência sobre os demais países devido ao seu desenvolvimento econômico e seu estilo de vida. No que se refere ao Ensino de Biologia, a política e o desenvolvimento científico tecnológico, desenvolvido pelos EUA, tem influenciado constantemente o Ensino de Biologia no mundo e especialmente no Brasil o que tem refletido diretamente na forma de lecionar essa disciplina no país.

Observa-se que em função da influência dos EUA, o Ensino de Biologia tem acompanhado uma série de modificações teóricas e epistemológicas ao longo de sua sistematização, muito embora ainda resista à concepção de um ensino descontextualizado com a realidade dos estudantes, o que tente a dificultar a aprendizagem, uma vez que não considera o cotidiano dos alunos, neste contexto, o ensino passa a assumir uma configuração monótona, distanciando-se da possibilidade de uma formação que promova a transformação social e formação crítica dos alunos, conscientizando-os acerca do seu papel na sociedade, além de conceber a ideia de uma Biologia pura e indispensável para o progresso e bem estar social. 
Todavia as pesquisas no campo do Ensino de Biologia tem apontado que essa perspectiva tem encontrado diversas críticas quanto ao formato estabelecido em relação ao processo de ensino principalmente a partir do movimento estabelecido no campo do Ensino de Ciências denominado Ciência, Tecnologia, Sociedade e Ambiente (CTSA), onde no bojo de suas concepções busca aproximar a ciência das pessoas à medida que desmistifica a sua tradicional imagem essencialista e neutra, questionando sua aplicabilidade como atividade inevitável e benfeitora em última instância através de indagações acerca dos problemas socioambientais causados pelo progresso científico e tecnológico.

Em relação ao exposto, Freitas e Marques (2017), ao realizarem uma pesquisa sobre abordagens a cerca de sustentabilidade no ensino Ciência, Tecnologia e Sociedade (CTS), apresentaram em seus resultados que as previsões de um amanhã, compatível com a possibilidade da espécie humana evitar sua própria extinção ou, pelo menos, retardá-la ao máximo, apresentam-se crescentemente temerária. Afirmam os pesquisadores nos resultados de suas pesquisas que vários eventos inter-relacionados configuram a crise ambiental (MARQUES, 2015). Nesse contexto de cenários insólitos, o autor cita as pesquisas de Veiga (2010) para exemplificar que não podemos pensar em "[...] suspender o processo antrópico, mas sim o agir no sentido de que não seja ainda mais acelerado do que já o foi, por conta das atividades humanas" (VEIGA, 2010, p. $33)$.

Por conseguinte, os pesquisadores relatam em seus achados que a "[...] busca pela sustentabilidade na dimensão ambiental compreende, entre outras medidas, o uso racional dos recursos naturais e a melhoria na eficiência técnica quanto às transformações materiais e ao uso de energia” (MARQUES et al., 2014, p. 80).

Neste sentido, recorrendo-se as pesquisas desenvolvida por Veiga (2010), encontra-se nos resultados o indicativo de que não podemos deixar de desconsiderar tais dimensões, haja visto que “[...] seria simplesmente complexo pensar em sustentabilidade diante da suprema humilhação da própria espécie humana, da privação de suas liberdades e da estupidez de seus morticídios" (VEIGA, 2010, p. 37).

Observa-se com isso que os achados das pesquisas desenvolvidas por Freitas (2012) e Veiga (2010) apontam para a perspectiva da sustentabilidade como um novo valor o que demandará a inserção em todos os contextos societários. Sendo assim, a educação passa a constituir-se num desses contextos, capaz de favorecer a apreensão da 
realidade socioambiental, nas intricadas relações sociedade e natureza, ao mesmo tempo em que contribui para a compreensão fundamentada sobre os elementos que desenham a atual crise ambiental.

Nesta perspectiva, as pesquisas desenvolvidas por Freitas (2012) e Veiga (2010) aponta que o desafio da Biologia passa a não ser apenas o de deter e explicar conceitos já preestabelecidos, mas propiciar uma alfabetização científica, que assegure aos estudantes uma compreensão plena, onde ele possa relacionar cada invenção e avanço científico, advindo da tecnologia, à sua finalidade, bem como as relações que o mesmo estabelece no contexto sócio ambiental. Com isso, a alfabetização cientifica passará a contribuir com o desenvolvimento da autonomia das pessoas, as quais passarão a ter a liberdade para tomar decisões conscientes, uma vez que elas terão uma percepção mais crítica, o que possibilitará a redução de desigualdades ocasionadas muitas vezes pela falta de informações, ou ainda a informação sem aspecto construtivo.

Para tanto, é preciso que haja uma mudança nos currículos das escolas quanto ao ensino científico, incorporando práticas e metodologias que propiciem a aprendizagem e a compreensão dos eventos cotidianos, favorecendo uma análise crítica em todas as proporções. Portanto o Ensino de Biologia passa ser uma ação que nos possibilitará refazer e reconstruir sociedades, assim como, estabelecer uma relação harmoniosa para com as pessoas e também para com outros seres vivos. Nesse contexto, a Educação Ambiental e os debates sobre sustentabilidade tornam-se necessárias, haja vista a necessidade da humanidade repensar seu estilo de vida, desenvolver atitudes que possibilite a percepção sustentável, utilizando de seus recursos, sem, contudo, extinguilos.

Nas pesquisas desenvolvidas por Roos e Becker (2012), encontra-se que os diversos problemas relacionados ao meio ambiente ainda existem porque as pessoas ainda não foram devidamente sensibilizadas o suficiente para compreender o quão delicado é o equilíbrio dos ecossistemas, ou seja, elas não estão habilitadas a dimensionar e solucionar efetivamente os problemas reais do seu cotidiano. Os resultados de suas pesquisas apontam ainda para a defesa de uma Educação Ambiental como uma ferramenta promotora de consciência sobre o que é sustentabilidade, visto que, uma abordagem sobre desenvolvimento sustentável está pautada na educação como alicerce para fundamentar um conceito que de fato promova a sustentabilidade. 
Lima (2003), ao desenvolver uma pesquisa sobre sustentabilidade e ensino, apontou nos resultados de seus estudos que [...] primeiramente, observa-se na educação para a sustentabilidade uma tendência a destacar a necessidade de mudanças de atitudes e comportamentos individuais em detrimento de mudanças que envolvem processos políticos e econômicos. Assim, para Lima (2003), os problemas socioambientais aparecem mais relacionados à esfera privada do que à esfera pública, e supõem uma falta de responsabilização dos agentes coletivos públicos e privados, como por exemplo, o Estado e as corporações globais.

Ventura e Souza (2010), defendem que por ser um espação de tensões ideológicas e políticas, a Educação Ambiental surge como uma proposta para confrontar esse desequilíbrio através de articulações entre as dimensões socioambientais.

Diante desta contextualização e dos avanços apontados pelos pesquisadores, há um questionamento, o Ensino de Biologia, dentro da perspectiva CTSA, ao abordar as dimensões educação ambiental e sustentabilidade, têm alcançado seus propósitos educacionais? Sua abordagem em sala de aula tem proporcionado aos estudantes uma transformação de pensamento e atitudes? O ensino sobre Educação Ambiental e Sustentabilidade tem colaborado para que os estudantes se tornem aptos a enfrentar os desafios da sociedade contemporânea? Como tem sido o debate sobre Educação Ambiental e Sustentabilidade nas aulas de Ciências dentro da perspectiva (CTSA)?

Tal estudo é importante para analisar como a educação ambiental bem como o conceito de sustentabilidade tem sido abordado na escola, a fim de compreender como esse processo tem sido compreendido pelos estudantes. Quanto ao tema, tem-se um interesse particular, visto que estas discursões visam promover um pensamento crítico e mudanças de comportamentos, concepções necessárias para promover uma atitude consciente e equilibrada diante do meio ambiente, tendo em vista uma relação harmônica. O estudo contribuirá ainda para que os professores possam utilizar as concepções aqui apresentadas e desenvolver ações didáticas junto aos educandos a fim de fortalecer o processo de ensino, de aprendizagem e práxis pedagógica.

\section{OBJETIVOS}


Analisar como o ensino de Biologia e a Educação Ambiental associada à Sustentabilidade tem contribuído para a formação de estudantes no contexto da Ciência, Tecnologia, Sociedade e Ambiente (CTSA) e para a o trabalho interdisciplinar.

\section{REFERENCIAL TEÓRICO}

\section{Aspectos Históricos e Sociais do Movimento Ciência, Tecnologia, Sociedade e Ambiente - CTSA.}

Apesar da data referente ao início do movimento Ciência, Tecnologia, Sociedade e Ambiente - (CTSA) não possuir uma precisão, podemos destacar que em meados do século XX, ao longo da segunda Guerra Mundial, ampliou-se as discussões referente aos aspectos científicos, tecnológicos e os impactos ocasionados na sociedade pela referida guerra (MORAES e ARAÚJO, 2012, p. 39 e 40). As discussões formam iniciadas a partir do contex to norte-americano e europeu.

Nos Estados Unidos, segundo Cerezo (2002, p.08), o movimento surge a partir de uma concentração o qual referia-se as consequências sociais e aos aspectos ambientais, sobre os produtos tecnológicos. Moraes e Araújo (2012) destaca que essa abordagem contribui para o surgimento da percepção (CTSA) nas décadas de 1960 e 1970 face aos movimentos ativistas e protestos sociais.

No contexto europeu o movimento (CTSA) é percebido por meio de investigações acadêmicas as quais divergem das concepções norte-americanas. Segundo Pinheiro (2005, p.32), há um destaque nas proporções sociais diante dos avanços científicos e tecnológicos, concentrando-se nos processos metodológicos, tendo em vista a explicação referente a origem das teorias cientificas.

Para Moraes e Araújo (2012, p.51 e p.55), o movimento passa a ser discutido na América-Latina, a partir das ponderações que apontam a Ciência e a Tecnologia como competências de políticas públicas. O autor ressalta que no Brasil o movimento surge de forma tímida todavia apresenta um expansão considerável quanto a perspectiva (CTSA) no âmbito do contexto educacional do país. A exemplo do exposto, os autores citam as linhas de pesquisa que foram criadas em vários cursos de graduação e pósgraduação, além da integração de disciplinas.

A proposta defendia a necessidade do governo brasileiro oferecer conteúdos e métodos de ensino que favorecessem aos estudantes uma formação científica mais 
"eficiente", visando o desenvolvimento do país segundo os interesses do governo americano, visto que o mesmo considerava de suma importância que o ensino de Biologia fosse mais atualizado e mais eficiente (KRASILCHIK, 1987; NASCIMENTO et al, 2010).

Entretanto, durante as décadas de 1960 e 1970 houve varias transformações no campo das ciências, haja visto que o desenvolvimento científico já não dava conta dos problemas da humanidade. Desta forma essa concepção passa a ser substituída por uma visão mais crítica das relações entre ciência, tecnologia e sociedade, devido o aumento da degradação ambiental e associação do desenvolvimento científico com os instrumentos de guerra, como as bombas atômicas utilizadas durante a II Guerra Mundial e o agente laranja utilizado pelos Estados Unidos na guerra do Vietnã (AULER, 2002).

É nesse contexto de crítica ao modelo de desenvolvimento científico, de impacto ambiental e reflexões sobre o papel da ciência na sociedade que surge o movimento Ciência-Tecnologia-Sociedade-Ambiente (CTSA), o qual busca problematizar a atividade científico-tecnológica como uma construção histórico-social, onde a educação passa a ser vista como ferramenta imprescindível para a formação de um cidadão com pensamento crítico, reflexivo, autônomo, atuante e apto para o exercício da cidadania, concepção essa defendida por Bazzo (2011, p.11) ao destacar que é necessário “[...] pensar na possibilidade de uma educação tecnológica reflexiva, questionadora, responsável perante o desenvolvimento social do ser humano".

Neste sentido, os estudos sobre o movimento CTSA como campo interdisciplinar tem origem nos movimentos sociais das décadas de 1960 e 1970, tendo início com o agravamento dos problemas ambientais decorrentes do desenvolvimento das ciências tecnológicas (SANTOS E MORTIMER, 2001).

Diante da necessidade de inclusão dos aspectos étnicos - ambientais nos estudos da ciência e tecnologia surge o conceito CTSA, o qual possui como principais desafios a abordagem de questões sociais e ambientais à luz de suas relações com a ciência e a tecnologia (HOFFMANN, 2011, p. 194). A fusão entre ciência, tecnologia, sociedade com a educação ambiental (CTSA), apenas foi possível devido ao reconhecimento da abordagem interdisciplinar, uma formação cidadã crítica - participativa, utilização de uma metodologia por temas ambientais, ensino contextualizado, a construção de habilidades e atitudes em busca de um desenvolvimento sustentável, que promova 
qualidade de vida e os conteúdos trabalhados a partir da realidade social na qual os alunos estão inseridos (LEMOS 2013).

Fagundes et al (2009), defendem a inserção da temática CTSA a partir de uma mudança curricular nas escolas, bem como a elaboração de projetos e/ou práticas educativas que possibilitem a compreensão dos fenômenos que ocorrem em nosso cotidiano, promovendo com isso uma percepção crítica da Ciência e da Tecnologia em todas as suas dimensões, sejam elas, culturais, éticas, ambientais, ou ainda, relacionadas à preparação para o trabalho. Essa mudança curricular torna-se necessária a medida que se exige uma reorientação nos saberes ensinados e nas práticas pedagógicas (RICARDO, 2007).

\section{Educação Ambiental e Sustentabilidade com Enfoque CTSA}

Com o desenvolvimento da revolução industrial associada às inovações tecnológicas e cientificas provocou uma maior demanda de matéria prima e consequentemente, maior degradação do meio ambiente, impulsionando com isso o consumismo exacerbado face ao avanço do capitalismo. O contexto referido passou a causar danos ao meio ambiente, podendo ser percebida no cotidiano como emissão de gases poluentes, aquecimento global, avanço do processo de desertificação em áreas degradadas, derretimento das calotas polares e destruição da camada de ozônio (LOWI 2005).

Simultaneamente foi possível perceber o impacto desse processo no aumento das desigualdades sociais, crescimento da pobreza, fome e exclusão social (ARAUJO; MENDONÇA, 2009). Reverter essa situação, tornar-se-ia necessário mudanças significativas nos valores e atitudes gerados pela dinâmica de racionalidade oriundas do capitalismo (LEFF 2001).

Nesta perspectiva, o conceito sustentabilidade aparece em 1987, quando a Organização das Nações Unidade (ONU) ao divulgar o Relatório Brundtlandt, conhecido como "Nosso futuro comum", que resguarda a ideia de desenvolvimento sustentável como sendo a continuidade dos aspectos econômicos, sociais, culturais e ambientais da sociedade humana, busca o preenchimento das necessidades individuais e coletivas ao mesmo tempo em que se preserva a biodiversidade e os ecossistemas naturais para as futuras gerações (ARRUDA e QUELHAS 2010). 
Em 1992, na cidade do Rio de janeiro, a Rio - 92 apresenta o Tratado de Educação Ambiental para Sociedades Sustentáveis e Responsabilidade Global que dispõe sobre princípios e um plano de ação para educadores ambientais, indicando uma relação entre as políticas públicas de educação ambiental e a sustentabilidade. Para Jacobi (2003), o referido tratado enaltecendo os processos e os métodos atuantes na promoção do meio ambiente, voltados para recuperação, conservação e melhoria do meio, propiciando uma melhora na qualidade de vida.

A articulação, sustentabilidade com o enfoque CTSA, pode ser abordado a partir de temas comuns a nossa sociedade, tais como, pobreza, fome, violência, desigualdade sociais, degradação do meio ambiente, escassez de recursos e etc. Essa articulação implica na maneira como a humanidade vem percebendo os impactos no ambiente em função das inovações tecnológicas e cientificas. Desta forma, pensar a sustentabilidade a partir desta articulação, implica na superação de paradigmas e consequentemente numa transformação na ordem econômica, política e cultural, bem como transformação na consciência, conhecimentos e comportamentos humanos.

Nesta perspectiva, a Educação Ambiental passa a integrar processos estratégicos com o propósito de formar o valores, habilidades e competências para orientar a a sustentabilidade (LEFF 2001, p. 237). Desta forma a Educação Ambiental delineia uma possibilidade de superar a tendência hegemônica da ecoeficiência e formar pessoas críticas, capazes de tomar decisões sobre os problemas que perpassam a ciência, a tecnologia, as questões sociais e ambientais (FARIAS E FREITAS, 2007).

\section{PERCURSO METODOLÓGICO}

A pesquisa configura-se como sendo do tipo quali-quantitativa, haja visto a compreensão integrada dos fenômenos em detrimento de conceitos específicos, aspirações, crenças, valores e atitudes restritas à operacionalização de variáveis, conforme descrito por Minayo (2001). Neste sentido, considerando os objetivos proposto, a pesquisa configura-se ainda como sendo exploratória.

Para Gil (2007), a pesquisa do tipo exploratória possibilita uma maior interação entre o pesquisador, o fato ou fenômeno pesquisado, aumentando o seu conhecimento sobre a temática, visto que envolve a participação de indivíduos no ambiente onde ocorre a situação alvo da pesquisa.

A pesquisa foi realizada durante o mês de maio de 2019 na escola E.E.M. Virgílio Távora localizada na cidade de Barbalha no Estado do Ceará. Participaram da 
pesquisa 20 (vinte) estudantes regularmente matriculados no $2^{\circ}$ ano do Ensino Médio, com idades que variam entre 16 e 17 anos. De forma a respeitar as aspectos éticos da pesquisa, foi solicitado a autorização da escola, dos pais e dos alunos a participação na da pesquisa.

Foi utilizado um questionário constando 10 (dez) questões semiestruturadas. O questionário constitui um dos procedimentos metodológicos mais utilizado em pesquisas qualitativas para obtenção das informações (SZYMANSKI, 2004). Este instrumento possibilita para as pesquisas qualitativas o diálogo compreensivo onde o pesquisador acolhe com respeito às colaborações dos participantes da pesquisa, minimizando a hierarquia e as relações de poder que, porventura, possam vir a existir, durante a realização da pesquisa ou ainda entre pesquisador e sujeito participante.

O questionário semiestruturado, foi elaborado a partir de tópicos estabelecidos previamente, ao tempo em que esteve aberto para novas informações que pudessem surgir no decorrer do processo de utilização do instrumento.

Para análise dos dados foram utilizadas duas formas básicas e complementares, são elas a decodificação dos questionários por meio da análise de conteúdo e a descrição etnográfica da observação participante sobre a visão dos participantes pesquisados.

A análise de conteúdo pode ser compreendida como um conjunto de métodos e procedimentos para exame das comunicações aspirando encontrar, através de processos sistemáticos e objetivos de descrição do conteúdo de mensagens, indícios que possibilite a dedução de conhecimentos relacionados a elaboração e a receptividade da mensagem (BARDIN,1977; MEIRELES E CENDÓN, 2010).

O emprego da etnografia não se limita apenas a estabelecer relações, definir informações, reproduzir um assunto, investigar genealogias ou mapear campos, ela empreende todo um esforço intelectual para uma descrição profunda (MATOS, 2011; GEERTZ, 1989, p. 15). O uso desta metodologia visa a obtenção de uma descrição densa e holística sobre o que determinado grupo de pessoas fazem ou pensam, bem como suas concepções sobre determinados pontos de vista (MATOS,2011).

Respeitando os aspectos éticos que envolvem a pesquisa, conforme apresentado anteriormente, e tendo em vista a Resolução 510/2016 do Conselho Nacional de Ética em Pesquisa com Seres Humanos (CONEP), os participantes deste estudo foram 
esclarecidos sobre os riscos /benefícios da pesquisa bem como a liberdade de desistir a qualquer momento. Foi apresentado que os mesmos estão assegurados quanto a preservação dos dados, sua confidencialidade e anonimato, conforme esclarecido no termo de assentimento e de consentimento livre e esclarecido (TCLE).

\section{RESULTADOS E DISCUSSÃO}

Os dados abaixo correspondem à colaboração dos 20 (vinte) alunos do $2^{\circ}$ ano de Ensino Médio. Os dados obtidos durante a aplicação dos questionários serão apresentados ao longo desta seção.

Inicialmente foi indagado aos estudantes sobre a abordagem referente a educação ambiental e sustentabilidade na escola. Dos vinte (20) alunos entrevistados, 14 afirmaram que sim, 4 informaram que não existia esta abordagem e 2 alunos não responderam. Os dados indica que a instituição discute a abordagem referente a educação ambiental e sustentabilidade conforme está previsto nas propostas dos Parâmetros Curriculares Nacionais (PCN), o qual enfatiza que "os conteúdos sobre meio ambiente serão integrados ao currículo através da transversalidade, tratados nas diversas áreas do conhecimento, de modo a impregnar toda prática educativa e, ao mesmo tempo, criar uma visão global e abrangente da questão ambiental" (PCN, 1997, p.36).

Essa prática vai de encontro ao que Mello, (2017) defende, uma escola que atua como veículo disseminador e transmissor de informações relativas ao meio ambiente, cujos objetivos está em tornar os estudantes mais críticos e conscientes do seu papel, quanto cidadão na sociedade, portanto, a escola deverá capacitar os jovens a tornaremse agentes transformadores do seu contexto social, disseminando os conhecimentos adquiridos em sala de aula.

Em seguida foi tratado sobre a educação ambiental e a forma como está é abordada na escola e se a mesma promove uma reflexão no contexto social, científico, tecnológico e ambiental (CTSA) e em casos afirmativos, qual a frequência de ocorrência. Na visão de 8 estudantes, esta análise ocorre frequentemente, muito embora 4 alunos relatarem ocorre muito pouco, e 7 relatam ocorre raramente. Do exposto um aluno se absteve. Neste contexto, não existe um consenso em relação a frequência com que ocorre esta abordagem na escola. 
A questão apresentada pelos alunos apresenta-se dentro de um processo complexo, visto que a Educação Ambiental só alcançará seu propósito de conscientização e formação crítica em sua totalidade, se for trabalhada em todos os contextos conforme enfatiza Bocheco (2012)

O Enfoque [...] CTS presume uma educação científica e tecnológica fundamentada na ação e construção social e que seja culturalmente e socialmente contextualizada. Para isso trata a ciência, a tecnologia e o seu ensino de forma a influenciar a vida cotidiana de estudantes e professores" (BOCHECO, 2012, p.39).

Em relação aos estudantes que afirmam que a discussão ocorre raramente, está questão nos remete a percepção de uma educação ambiental que ocorre esporadicamente, desconsiderando aspectos importantes para se conceber uma formação ampla e integradora, isto é, não está sendo trabalhado como tema transversal, sendo portanto assunto peculiar a todas as disciplinas conforme orienta os PCN'S (PCN BRASIL,1998).

Ao questionar os alunos se as atitudes desenvolvidas por eles desenvolvidas configuram-se como sendo sustentáveis, 14 alunos afirmaram que sim, que sempre adotam hábitos que não causam danos ao meio ambiente, como fechar a torneira enquanto escova os dentes, jogar o lixo no lixo e reduzir o uso de produtos descartáveis. Outros 4 alunos afirmaram que adotam estes hábitos frequentemente e estão sempre atentos as questões ecológicas, e apenas 2 alunos declararam que raramente adota atitudes sustentáveis, tendo como justificativa que não é algo fácil, e que não sabem lidar com essas questões. Sobre o exposto destacam-se:

"Não jogar lixo em rios e etc, e sempre descartar o lixo em locais apropriados". (Aluno 7)

"Reutilizar a água da máquina de lavar e evitar usar copos descartáveis". (Aluno13)

Face ao exposto, fica evidente a necessidade de uma educação voltada para soluções dos problemas que se apresentam no dia a dia. Desta forma se faz necessário que a abordagem CTS e EA pleiteiem uma educação voltada para elucidar as essas questões, a fim de exercitar nos educandos a capacidade de tomar iniciativas sustentáveis e promover o pensamento crítico-reflexivo, a autonomia mudanças de atitudes e condutas, seja socialmente quanto socioambientalmente (HANSEN ET AL, 2019; BOURSCHEID \& FARIAS , 2014). 
Em seguida questionou-se se a temática sustentabilidade associada a educação ambiental é algo trabalhado no cotidiano escolar, seja na teoria quanto na prática. Para 7 estudantes sim, visto que a escola desenvolve projetos voltados para esta área temática que envolve toda a escola. Na percepção de outros 6, a escola aborda o assunto apenas na teoria, mas não incentiva a prática. Para outros 3, raramente se discute temas ambientais, e quando o faz, não relaciona ao dia a dia dos estudantes e 3 discentes argumentam ainda que teoria e práticas só é abordada durante dias comemorativos, como o dia da árvore, água e meio ambiente.

Isso nos remete a necessidade de uma educação ambiental contínua, onde os estudantes terão acesso as informações e saberes relacionadas ao meio ambiente, compreendendo seu papel na preservação do meio ambiente e agente transformador (MELO, 2017).

Durante a realização da pesquisa, 14 aluno relataram que além de abordar os problemas sociais e ambientais atuais, a escola poderia investir no direcionamento sobre como agir de forma sustentáveis a fim de mudar os impactos existentes no ambiente, trabalhando atitudes simples como a adoção de 5R'S. 3 estudantes destacam que as abordagens são superficiais, não contribuindo para a mudanças que se deseja e 3 não opinaram.

O incentivo a iniciativas simples podem contribuir com transformações importantes. Para Rosa e Strieder (2018, p. 4) o processo democrático se estabelece com o aumento do engajamento dos discentes no âmbito escolar, com voz ativa e ouvida no contexto educacional, despertando para a problematização e modificações de circunstâncias vivenciadas, promovendo na sua família e em sua comunidade uma maior sensibilização sobre a importância de se preservar o meio ambiente, bem como os recursos naturais.

A prática dos 5 R`S refere-se aos termos, reduzir, reutilizar, reciclar, que se constitui importante alternativa para diminuir a quantidade de resíduos, buscando aumentar o tempo de vida útil dos aterros sanitários, reduzindo o consumo de matéria prima, a demanda por energia e etc. Além dessas três ações é importante que se associe a outras duas, que são elas, repensar e recusar, visto que é preciso repensar os nossos hábitos de consumo, que muitas vezes é insustentável, bem como recusar produtos que cause grande dano ao meio ambiente, a saúde e outros seres vivos, evitar a compra de produtos supérfluos, atribuir novas funcionalidades aos produtos antes de descarta-los e 
quando o fizer, buscar um local apropriado para que o mesmo venha ser reciclado (ANTQUEVES ET AL, 2015; COMINI ET AL., 2007).

Alinhar teoria á prática, propicia valores e aprendizagens que direcionam para um ensino que visa o desenvolvimento de uma sociedade sustentável, onde a EA apresenta-se integrada ao currículo escolar, comprometida com os objetivos do movimento CTS. Desta forma destaca-se que os valores cognitivos proporcionados pela prática apontam para uma política de desenvolvimento de uma sociedade sustentável, no qual promove-se a interdisciplinaridade, o incentivo, a responsabilidade e o compromisso diante das problemáticas ambientais atuais (HANSEN ET AL, 2019).

Sobre os fatores que contribuem para a degradação ambiental, 6 estudantes destacaram a falta de informação associada ao uso exacerbado de produtos descartáveis, 11 estudantes relataram que a principal razão consiste na falta de consciência ambiental das pessoas. 3 aluno associaram a degradação a falta de interesse das pessoas em relação ao assunto. 2 aluno destacam a obsolescência programada dos produtos tecnológicos como a principal causa de degradação do meio ambiente, e uma aluna destacou que tal situação resulta da indução ao consumismo.

Sabe-se que grande parte da produção de resíduos sólidos está associada aos padrões culturais, condições econômicas e hábitos de consumo, sendo este último um dos maiores responsáveis pela grande quantidade de resíduos produzidos. Esta problemática se estrutura devido as demandas por artefatos oriundo do consumo exacerbado, assim como devido as empresas e grandes conglomerados econômicos não demonstrarem interesses em solucionar os problemas ambientais, consequentemente produzem embalagens inadequadas, desperdiço de matéria prima e promoção da degradação ambiental (ROTH \& GARCIAS, 2009). Para Lantouche (2012, p. 30),

são necessários três ingredientes para que a sociedade do consumo possa prosseguir o seu circuito diabólico: a publicidade, que cria o desejo de consumidor, o crédito, que lhe fornece os meios, e a obsolescência acelerada e programada dos produtos que, renova a sua necessidade (LANTOUCHE, 2012, p. 30).

O consumismo associado a obsolescência programada provoca ao meio ambiente danos imensuráveis para além do que o planeta pode suportar. Por tanto existe a necessidade urgente de se repensar os hábitos de consumo, reutilizar produtos e que as empresas possam adotar políticas éticas no sentido de produzir produtos de qualidade com maior durabilidade e de proteção para o meio ambiente e saúde da população. 
Em relação a abordar os conteúdos referente ao meio ambiente em outras disciplinas e não apenas ciências, 17 estudantes afirmaram que sim, 3 estudantes afirmaram não ser importante. Os estudantes que consentiram positivamente destacam que a abordagem sobre o tema é importante para o meio ambiente, amplia os conhecimentos sobre o assunto e sua discursão promove iniciativas e desenvolve a conscientização dos alunos por meio de ações interdisciplinaridade. A exemplo do exposto, os alunos destacam:

"Muitas pessoas não tem a consciência sobre o assunto em, dessa forma acredito que tenha que ser estudado em todas as disciplinas". (Aluno 9).

"Eu acho que esse conteúdo não diz respeito a uma única disciplina". (Aluno 18)

Ao abordar assuntos sobre o meio ambiente, Oliveira et al, (2012), defende que este deva está incluso no currículo e deve ser trabalhado como assunto transdisciplinar, sendo portanto cabível em todas as áreas do conhecimento, afim de garantir ao estudante o mínimo de conhecimentos básicos essenciais. Desta forma cabe a escola possibilitar aos estudantes atividades que lhe propiciem situações onde ele possa colocar em práticas estas atitudes, preparando-os para vivenciar no seu cotidiano o que foi abordado teoricamente na escola.

Para Vasconcelos e Freitas (2012) assim como para Veiga (2005), a interdisciplinaridade corresponde a ponte para edificação de uma consciência sobre sustentabilidade, uma vez que possibilita ferramentas para superar os problemas presentes na sociedade atual. Abordar a Educação Ambiental e sustentabilidade de forma restrita limita a compreensão sobre as ciências e desta forma não contribuirá para compreensão acerca dos desafios que estão implícitos na sociedade. Desta forma tornase necessário construir uma visão mais ampla sobre essa problemática, possibilitando uma maior reflexão sobre o estágio atual de desenvolvimento (VASCONCELOS E FREITAS, 2012; VEIGA, 2005).

Sobre como a Educação Ambiental é discutida em sala de aula, de forma a contribuir para mudar a realidade socioambiental, 14 estudantes destacam possuírem dúvidas quanto ao real impacto sobre mudar a realidade. Destaca-se as seguintes falas:

"Para alguns sim, mas para quem não presta atenção não vai fazer diferença nenhuma". (Aluno15) 
"De uma forma razoável. Se cada um fizer o básico, já haverá grande mudança". (Aluno16)

A educação nas escolas tem a finalidade de discutir a problemática ambiental, visando a formação crítica e consciente dos estudantes, habilitando-os para enfrentar os desafios atuais e concedendo-lhe autonomia para tomar decisões e atuar em sua realidade. Cabe à escola fornecer um ambiente propício e fornecer orientações a fim de obter êxito nas ações referente a Educação Ambiental. Desta forma os professores devem desenvolver reflexões e debates sobre as questões ambientais e assim contribuir para a construção de conceitos que favoreça a construção do conhecimento sobre Educação Ambiental e Sustentabilidade (MELO 2017).

Por fim, buscou-se compreender se os estudantes desenvolvem ações sustentáveis junto à comunidade e no convívio familiar.14 estudantes afirmaram que sim, enquanto 6 afirmaram desenvolver ações esporádicas, não sendo, portanto algo praticado no dia a dia. Essa situação pode estar atrelada a falta de responsabilização dos indivíduos, derivado da falta de informação e de uma consciência ambiental, bem como pela ausência de hábitos sustentáveis na comunidade e no convívio social, sendo necessário portanto sistematizar ações que envolva a participação de todos (JACOBI, 2003).

Portanto a escola tem a responsabilidade de sensibilizar os estudantes no sentido de prepará-los para o desenvolvimento de atitudes sustentáveis que transcendam o ambiente escolar, promovendo nestes a criticidade e uma mudança de pensamento, envolver os alunos em projetos ambientais e situações reais que os prepare para os desafios que deverão ser enfrentados na perspectiva de um futuro sustentável (EFFTING, 2007).

\section{CONCLUSÃO}

Embora a escola aborde esta temática durante as aulas, pode-se perceber que a forma como o debate tem ocorrido não conseguiu promover nos estudantes uma consciência e uma formação crítica quanto sua atuação frente aos desafios socioambientais presentes na sociedade. Percebe-se ainda que, por muitas vezes os temas são abordados apenas no âmbito teórico sem relacionar com o cotidiano dos estudantes e restrito a disciplina de Biologia. 
O estudo demonstra que a abordagem ambiental resultará em mudanças quando associada a práticas que estimulem os estudantes vivenciar esta aprendizagem em sua comunidade por meio de atividades interdisciplinares a partir de situações problemas que promova nos alunos a reflexão sobre como resolver as problemáticas que perpassam as questões ambientais.

Ainda que os estudantes tenham apontados que os debates ocorram de forma frequente, a forma como tem ocorrido não tem preparados os estudantes para mudar os hábitos, assim como promovido neles a criticidade. Restringir o debate apenas a ações simples e pequenas, embora importante, as mudanças significativas somente aparecerão quando associada a ações mais ampla, como por exemplo, promoção de mutirões de limpeza de um rio, trilhas ecológicas com o objetivo de conhecer os impactos do descarte do lixo próximo a mananciais, visita a áreas degradas devido ao desmatamento e discussão crítica e reflexiva sobre os meios para solucionar tal problemática.

Através deste trabalho pode-se observar a necessidade de se repensar os currículos escolares, bem como a forma de trabalhar a Educação Ambiental, buscando não restringir essa abordagem apenas a disciplina de Ciências ou de Biologia, mas trabalhar essa problemática dento do contexto interdisciplinar com foco no movimento CTSA. Ressalta-se a necessidade de que as práticas sustentáveis sejam trabalhadas e incentivadas diariamente na escola, e não apenas em datas comemorativas.

Aos professores, cabe investir na formação continuada dos mesmo, no sentido de ampliar as concepções teóricas e epistemológicas sobre a problemática com vista ao desenvolvimento de uma ação docente para além da disciplina, o que colabora para a organização didática das aulas com abordagens críticas e reflexivas sobre a ação do homem no meio ambiente.

Sendo assim, alcança-se o objetivo proposto neste trabalho referente a análise do alcance dos propósitos educacionais do Ensino de Biologia, dentro da perspectiva (CTSA), ao abordar as dimensões Educação Ambiental e sustentabilidade. A pesquisa possibilitou ainda, identificar a partir dos estudantes, que somente será possível reverter este cenário quando cada um atuar como coparticipante do processo, essa percepção apresenta-se como sendo o primeiro passo para ser trabalhada a sensibilização no sentido de construir em cada um o desejo de promover mudanças. Desta forma torna-se importante compreender que a Educação Ambiental e a Sustentabilidade devem ser amplamente discutidos e vivenciado todos os dias em todas as esferas sociais, e é 
função da escola preparar os estudantes para os desafios ambientais presentes na sociedade atual e futuras gerações.

\section{REFERÊNCIAS}

Prefácio. In: VEIGA, José Eli da. Desenvolvimento sustentável: o desafio do século XXI. Rio de Janeiro: Garamond, 2005. p. 9-11.

ANTQUEVES, L. M. C.; BOSA, C. R.; DUBIASKI-SILVA, J.; A Educação Ambiental e Atividades Lúdicas: Um incentivo a mudança de hábitos na geração de lixo. Remoa/ UFSM, v. 14, n. 2, mai-ago. 2015, p. 183-192.

ARAÚJO, G. C.; MENDONÇA, P. S. M. Análise do processo de implantação das normas de sustentabilidade empresarial: um estudo de caso em uma agroindústria frigorífica de bovinos. Revista de Administração Mackenzie, São Paulo, v. 10, n. 2, mar./abr., 2009.

ARRUDA. L; QUELHAS. O. L. G. Sustentabilidade: um longo processo histórico de reavaliação crítica da relação existente entre a sociedade e o meio ambiente. B. Téc. Senac: a R. Educ. Prof., Rio de Janeiro, v. 36, n.3, set./dez. 2010.

AULER, D. Interações entre Ciência-Tecnologia-Sociedade no contexto da formação de professores de ciências. 2002. 257f. Tese (Doutorado em Educação: Ensino de Ciências Naturais) - Universidade Federal de Santa Catarina, Florianópolis, 2002.

BARDIN, L. Análise de conteúdo. Lisboa: Edições 70, 1977. 226p.

BAZZO, W. A. Ciência, tecnologia e sociedade e o contexto da educação tecnológica. Florianópolis: UFSC, 2010. 287 p.

BAZZO, W. A. Ciência, Tecnologia e Sociedade e o contexto da educação tecnológica. 3. ed. Florianópolis (SC): UFSC, 2011.

BOCHECO, Otávio. Parâmetros para a Abordagem de Evento no Enfoque CTS.

Dissertação do Programa de Pós-Graduação em Educação Científica e Tecnológica da Universidade Federal de Santa Catarina. Data 25/10/2012. Disponível em: http://repositorio.ufsc.br. Acesso em mai 2019.

BOURSCHEID, J. L. W.; FARIAS, M. E. A convergência da educação ambiental, sustentabilidade, ciência, tecnologia e sociedade (CTS) e ambiente (CTSA) no ensino de ciências. Revista Thema | 2014 | 11 (01) 
CEREZO, J. A. L. Ciências, Tecnologia e Sociedade: o estado da arte na Europa e nos Estados Unidos. In: SANTOS, L. W.; ICHIKAWA, E. Y.; SENDIN, P. V. \& CARGANO, D.de F. (Orgs.). Ciências, Tecnologia e Sociedade: o desafio de interação. Editora IAPAR, Londrina - PR, p. 3 - 39, 2002.

COMINI G.S.; HONDA I.M.; FERNANDES J.C.; MACIEL M.S.D.; Digressão sobre a inserção da variável sustentabilidade socioambiental no planejamento estratégico das organizações. CEFET/RJ-CSF. Revista Tenda, 2007, n. 3. Disponível em: <https://www.ecodebate.com.br/2017/03/14> Acesso em: 21 mai. 2019.

EFFTING, T. R. Educação Ambiental nas Escolas Públicas: Realidade e Desafios. Marechal Cândido Rondon, 2007. Monografia (Pós Graduação em "Latu Sensu” Planejamento Para o Desenvolvimento Sustentável) - Centro de Ciências Agrárias, Universidade Estadual do Oeste do Paraná - Campus de Marechal Cândido Rondon, 2007.

FAGUNDES, S.M.K. et al. Produções em Educação em Ciências sob a perspectiva CTS/CTSA. Anais do VII Encontro Nacional de Pesquisa em Educação em Ciências (VII ENPEC), Florianópolis, p. 1-12, 2009.

FARIAS, C. R. DE F.; FREITAS, D. Educação ambiental e relações CTS: uma perspectiva integradora. Ciência \& Ensino, v.1, número especial, nov. 2007.

FREITAS, N. M. DA S; MARQUES, C. A. Abordagens sobre sustentabilidade no ensino CTS: educando para a consideração do amanhã. Educar em Revista, Curitiba, Brasil, n. 65, p. 219-235, jul./set. 2017.

GEERTZ, C. A interpretação das culturas. Rio de Janeiro: Guanabara Koogan, 1989. GIL, A.C. como elaborar projetos de pesquisa. 4. ed. São Paulo: Atlas, 2007.

GRIPPI S. Lixo: reciclagem e sua história: um guia para as prefeituras brasileiras. Rio de Janeiro: Interciência. 2001.

HANSEN, T. R.; MARSANGO, D.; SANTOS, R. A..; Práticas educativas CTS e educação ambiental na problematização dos valores presentes no direcionamento dado ao desenvolvimento científico-tecnológico. Rev. Eletrônica Mestr. Educ. Ambient. Rio Grande, Ed. Especial EDEA, n. 2, p. 118-129, 2019.

HOFFMANN, W. A. M. (Org.). Ciência, tecnologia e sociedade: Desafios da construção do conhecimento. São Carlos: EdUFUSCar, 2011. 
JACOBI, P.; Educação ambiental, cidadania e sustentabilidade. Cadernos de Pesquisa, n. 118, março/ 2003.

KRASILCHIK, M. O professor e o currículo das ciências. São Paulo: EPU/EDUSP, 1987.

LATOUCHE, S. O pequeno tratado do decrescimento sereno. reimp. Lisboa:

Edições 70, 2012.

LEFF, E. Epistemologia ambiental. São Paulo: Cortez, 2001.

LEMOS, J. L. S. Ciência-Tecnologia-Sociedade-Ambiente (CTSA). Revista ciências \& ideias. VOL. 4, N. 2. JAN/DEZ -2013 Editorial ISSN : 2176 - 1477.

LIMA, G. C. O discurso da sustentabilidade e suas implicações para a educação.

Ambiente \& Sociedade, Campinas (SP), v. 6, nº. 2, jul.,/dez., 2003.

LOWI, M. Ecologia e socialismo. São Paulo: Ed. Cortez, 2005.

MARQUES, C. A.; ROLOF, F. B.; MARCELINO, L. V.; BARBOSA, L. C. A.; MACHADO, A. R. Compreensões de pesquisadores químicos sobre sustentabilidade ambiental. Revista Brasileira de Ensino de Química, Campinas, SP: Editora Átomo, v. 9, n. 2, p. 79-92, 2014.

MARQUES, L. Capitalismo e colapso ambiental. Campinas, SP: Editora da Unicamp, 2015.

MATTOS, C.L.G. A abordagem etnográfica na investigação científica. In MATTOS, C.L.G., e CASTRO, PA., orgs. Etnografia e educação: conceitos e usos [online].

Campina Grande: EDUEPB, 2011. pp. 49-83.

MEIRELES, M. R. G. CENDÓN, B. V. Aplicação prática dos processos de análise de conteúdo e de análise de citações em artigos relacionados às redes neurais artificiais.

Revista Informação \& Informação, Londrina, v. 15, n. 2, p. 77-93, jul.-dez; 2010.

MELLO, L. G. A importância da Educação Ambiental no ambiente escolar. 2017.

Disponível em: < https://www.ecodebate.com.br/2017/03/14/importancia-da-educacaoambiental-no-ambiente-escolar-artigo-de-lucelia-granja-de-mello/. Acesso em:30 mai de 2019. 
MORAIS, J. U. P.; ARAÚJO, M. S. T. O Ensino de Física e o Enfoque CTSA:

Caminhos para uma educação cidadã. $1^{\text {o }}$ edição, Editora Livraria da Física. São Paulo: 2012.

MINAYO, M. C. S. (Org.). Pesquisa social: teoria, método e criatividade. Petrópolis: NASCIMENTO, F. DO.; FERNANDES, H. L.; MENDONÇA, V. M. DE.; O ensino de ciências no Brasil: História, formação de professores e desafios atuais. Revista HISTEDBR On-line, Campinas, n.39, p. 225-249, set.2010 - ISSN: 1676-2584.

PINHEIRO, N. A. M. Educação Crítico-Reflexiva para um Ensino Médio Cientifico-Tecnológicas: a contribuição do enfoque CTS para o ensino aprendizagem do conhecimento matemático. Tese (Doutorado em Educação Cientifica e Tecnológica). Universidade Federal de Santa Catarina, Florianópolis, 2005. OLIVEIRA, I. S. ; PINHEIRO, N. Z.; FREITAS, C. A.; MENEZES, P. H. D. Problemas ambientais locais: educabilidades possíveis a partir do enfoque CTSA. Disponível em: < http://www.nutes.ufrj.br/abrapec/viiienpec/resumos/R1009-1.pdf> Acesso em: 21 mai. 2019.

RICARDO, E.C. Educação CTSA: obstáculos e possibilidades para sua implementação no contexto escolar. Ciência \& Ensino, vol. 1, número especial, p: 1-12, 2007.

ROOS, A; BECKER, E.L.S. Educação ambiental e sustentabilidade. Revista Eletrônica em Gestão, Educação e Tecnologia Ambiental. REGET/UFSM (v(5), nº5, p. $857-866,2012$.

ROTH, C. G.; GARCIAS, C. M.; A influência dos padrões de consumo na geração de resíduos sólidos dentro do sistema urbano. Redes, Santa Cruz do Sul, v. 13, n. 3, p. 5 13, set/dez. 2009.

SANTOS, H. R., DOMINIQUINI, E. D. A insustentabilidade da obsolescência programada: uma violação ao meio ambiente e aos direitos do consumidor. Disponível em: <http://www.publicadireito.com.br/artigos/?cod=ea2af5ea4aabdca1> Acesso em: 21 mai. 2019.

SANTOS, W. L. P. dos; MORTIMER, E. F. Tomada de decisão para ação social responsável no ensino de ciências. Ciência e educação. Bauru, v.7, n.1, 2001. 
SILVEIRA, R. M. C. F. BAZZO, W. A. Ciência, tecnologia e suas relações sociais: a percepção de geradores de tecnologia e suas implicações na educação tecnológica.

Ciência \& Educação, Bauru, v.15, n. 3, p. 681-694, 2009.

SZYMANSKI, H. A entrevista na pesquisa em educação: a prática reflexiva. Heloisa szymanski (org), Laurinda Ramalho de Almeida, Regina Célia Almeida Rego Prandini,Brasília :1.ed. Liber Livro, 2004.

TRAVASSOS, E. G. A prática da educação ambiental nas escolas. Porto Alegre, RS: Editora Mediação, 2.ed., 2006.

VASCONCELOS, E.R.; FREITAS, N. M.S. O paradigma da sustentabilidade e a abordagem cts: mediações para o ensino de ciências - Revista de Educação em Ciências e Matemáticas V.9 - nº 17 - jul. 2012/dez. 2012, p.89-108.

VEIGA, J. E. Sustentabilidade: a legitimação de um novo valor. São Paulo: SENAC, 2010.

VENTURA, G.; SOUSA, I. C. F. Refletindo sobre a relação entre Natureza humana, valores capitalistas e a crise ambiental: contribuições para a promoção da Educação Ambiental crítica. Ambiente e educação. Vol. 15 (1). 2010.

EWERLING DA ROSA, S.; STRIEDER, R. Dimensões da democratização da ciênciatecnologia no âmbito da educação CTS. Revista Insignare Scientia - RIS, v. 1, n. 2, 24 ago. 2018. 